TM-1672

\title{
Ternary Superconductor "NbTiTa" for High Field Superfluid Magnets *
}

\author{
A. D. McInturff, J. Carson \\ Fermi National Accelerator Laboratory \\ P.O. Box 500 \\ Batavia, Illinois 60510 \\ D. Larbalestier, P. Lee, J. McKinnel \\ University of Wisconsin-Madison \\ Madison, Wisconsin 53706 \\ H. Kanithi \\ IGC/Advanced Superconductor, Inc. \\ Waterbury, Connecticut 06704 \\ W. McDonald, P. O'Larey \\ Teledyne Wah Chang Albany \\ Albany, Oregon 97321
}

June 1990

* Submitted to the Intermag 90: International Magnetics Conference, Brighton, England, April 17-20, 1990. 


\section{TERNARY SUPERCONDUCTOR "NbTITa" FOR HIGH FIELD SUPERFLUID MAGNETS}

A.D. McInturff, J. Carson

Fermi National Accelerator Laboratory*

Batavia, Illinois, U.S.A.

D. Larbalestier, P. Lee, J. McKinnel

University of Wisconsin-Madison Madison, Wisconsin, U.S.A.

H. Kanithi

IGC/Advanced Superconductor, Inc. Waterbury, Connecticut, U.S.A. .

W. McDonald, P. O'Larey

Teledyne Wah Chang Albany

Albany, Oregon, U.S.A.

Abstract - The possibility exists to obtain a higher ' $\mathrm{Hc}_{2}$ ' upper critical field in the NbTi system which is normally limited by a spin-orbit coupling term. The introduction of scattering reduces this coupling. The spin-orbit scattering rate is proportional to $\mathrm{Z}^{4}$ and therefore leads logically to the introduction of a high atomic number element which is more or less similar with respect to all of the other properties, i.e., Tc. Previous studies have shown Tantalum to be an excellent choice. The present work represents an attempt to obtain a high current density, high field ternary magnet conductor ( $\mathrm{Jc}(10 \mathrm{~T}, 2 \mathrm{~K}$, $\rho$ eff $=$ $\left.\left.10^{-12} \Omega-\mathrm{cm}\right)\right)>2000 \mathrm{~A} / \mathrm{mm}^{2}$. This goal was met, but the conductor was clearly not optimized.

\section{INTRODUCTION}

In the last five to six years at Fermilab there has been a low level development program with the goal to fabricate high field, high current density superfluid helium accelerator magnets ${ }^{1}$. In conjunction and in collaboration with this program, there has been a metallurgical study to optimize the high field current density "Jc" of NbTiTa with its enhanced $\mathrm{Hc}_{2}$. This study has been done by the University of Wisconsin group utilizing the expertise and production capabilities of Intermagnetics General and Teledyne Wah Chang Albany. The optimization study proceeded at UW using small experimental composites and then later material from a $25 \mathrm{~cm}$ diameter extrusion. Simultaneously high homogeneity binary $\mathrm{Nb} 46.5 \mathrm{w} / \mathrm{oTi}$ composites were being optimized and fabricated thus providing a basis for a comparison. Three years ago, there arose a need for a high gradient quadrupole system for the new collision point in the Tevatron "Collider". One of the proposed lattices ${ }^{2}$ required a quadrupole winding with a peak field $>9 \mathrm{~T}$. This provided the incentive to process one or two $30.5 \mathrm{~cm}$ diameter

*Operated by Universities Research Association under contract with the U.S. Department of Energy billets of ternary alloy/copper composite into magnet conductor strand operating in superfluid helium at $1.8 \mathrm{~K}$.

\section{Historical Development of NbTiTa}

The first studies by Suenaga and Ralls ${ }^{3}$, of $\mathrm{Hc}_{2}$ for the ternary composition of $\mathrm{Nb}, \mathrm{Ti}$, and $\mathrm{Ta}$ occurred in 1968-1972. The first attempts to obtain high " $\mathrm{jc}$ (magnet conductor) were done in 1978 by Segal, et. al4. A more detailed study of $\mathrm{Hc}_{2}$ and "Tc" critical temperature was completed by Hawksworth and Larbalestier 5.6 in 1981 . Then in 1982, our initial study of NbTiTa was undertaken starting with a not completely chemically homogeneous alloy, namely Nb41.5w/oTi15w/oTa. This study resulted in a conductor which was apparently limited by A) poor chemical homogeneity; B) large local ratio of $\mathrm{Cu} / \mathrm{NbTi}$; and C) intermetallics (possibly). Also during this same time frame, the Japanese groups of Watanabe, et.al. ${ }^{7}$, and Wada, et.al. ${ }^{8}$ fabricated some ternary composites. The "Jc" values $(5 \mathrm{~T}, 4.2 \mathrm{~K})$ were $\sim 2000 \mathrm{~A} / \mathrm{mm}^{2}$ range and $" J \mathrm{c} "(8 \mathrm{~T}, 4.2 \mathrm{~K})<$ $900 \mathrm{~A} / \mathrm{mm}^{2}$ were obtained by these groups ${ }^{9}$. Then in 1986, with the increased fundamental understanding of "Jc" in the binary system for the $\mathrm{Nb} 46.5 \mathrm{w} / \mathrm{oTi}$ alloy and the need for a very high gradient lens in the Tevatron Collider, a high homogeneity "HiHo" alloy was fabricated utilizing the information acquired in the binary system studies and fabrication experience ${ }^{10}$. This diffusion barriered "HiHo" ternary alloy was fabricated into a $30.5 \mathrm{~cm}$ diameter $\mathrm{Cu}$ composite billet.

\section{The First NbTiTa Billet}

A production run of ternary $\mathrm{Nb} 41.5 \mathrm{w} / \mathrm{oT} i$ 15 w/oTa alloy was prepared. The amount of alloy made was $\sim 50 \%$ more than necessary to fabricate it $25.4 \mathrm{~cm}$ diameter copper composite billet at it $\mathrm{Cu} / \mathrm{NbTi}$ ratio of $1.5 / 1$. The alloy was forged. swaged, and finally drawn down to a rod size where 
it could be cleaned, straightened, and cut into billet length rods. The rods were then placed in OFHC copper hex rods. These composites then could be stacked in a copper can with an electron beam welded end plate and nose cone, thus completing a $25.4 \mathrm{~cm}$ billet prior to extrusion. The excess material was made into smaller multi-filament arrays; extruded, drawn, and precipitation heat treated. The cold work/heat treatment schedule for the larger billet was determined by the results obtained from these optimization studies of smaller arrays with respect to $5 \mathrm{~T}$ and $8 \mathrm{~T}$.

\section{The Second "HiHo" NbTiTa Billet}

A production run of "HiHo" ternary $\mathrm{Nb}$, $44.4 w / o T i 15.4 w / o T a$ alloy was prepared. The alloy was wrapped with $0.76 \mathrm{~mm}$ thick $\mathrm{Nb}$ foil at a $13.71 \mathrm{~cm}$ diameter and placed in a copper can to become a billet. The assemblage of copper, alloy, and foil was subsequently compacted by hot isostatically pressing "HIPed" for void removal and then extruded. This composite was subsequently cold area reduced, shaved, and hexed to the proper copper to superconductor volume ratio for the desired stacking spacing. The composite hexes were then cleaned, straightened, and cut to length for extrusion. The hexes were then stacked into a copper can, end plate and nose cone, with an electron beam welded assembly. This $30.5 \mathrm{~cm}$ diameter billet was "HIPed" and then extruded at as low a temperature as advisable. The extra material (the hex composite in excess of that required to fabricate the $30.5 \mathrm{~cm}$ diameter billet for a $1.5 / 1$ $\mathrm{Cu} /($ superconductor + barrier $))$ was utilized in smaller multifilament arrays. These smaller arrays were then processed as previously done with various parameters (cold work and heat treatment) in order to optimize them with respect to $\mathrm{Jc}(5 \mathrm{~T}$, $4.2 \mathrm{~K})$ and $\mathrm{Jc}(8 \mathrm{~T}, 4.2 \mathrm{~K})$ with emphasis on the latter.

\section{$\underline{\text { Results }}$}

The first billet had the following properties: the alloy composition and variation was Nb4lw/oTi, $15 w / 0$ Ta with 3 to 4 w/o variations globally. There were no local high $\mathrm{Ta}$ concentrations $(>4 \mathrm{w} / 0)$ as in previous production alloys. This composition and variation was verified with both $\mathrm{X}$-ray photo and electron probe, as well as the wet chemistry analysis. The electron probe results were $41.5 \mathrm{w} / \mathrm{oTi}$ and $15.0 \mathrm{w} / \mathrm{oTa}$ with the remainder being $\mathrm{Nb}$ with concentration variation of the constituents being $<4 \mathrm{w} / \mathrm{o}$. The production $25 \mathrm{~cm}$ billet strand fabricated using a three heat treatment/cold work schedule similar to the binary optimum reached a critical current density of $\mathrm{Jc}\left(5 \mathrm{~T}, 4.2 \mathrm{~K}, \rho\right.$ eff $\left.=10^{-14} \mathrm{ohm} \cdot \mathrm{m}\right)$ $=2200 \mathrm{~A} / \mathrm{mm}^{2}$ and $1230 \mathrm{~A} / \mathrm{mm}^{2}$ for Jc $(8 \mathrm{~T}, 4.2 \mathrm{~K}$, $\rho_{\text {eff }}=10^{-14}$ ohm $\left.-m\right)$. The best of the final strand had $\mathrm{Jc}\left(10 \mathrm{~T}, 1.9 \mathrm{~K}, \rho_{\text {eff }}=10^{-14}\right.$ ohm-m $)=$ $1850 \mathrm{~A} / \mathrm{mm}^{2}$. This represents a shift in the critical current curve of $4 \mathrm{~T}$ between $4.2 \mathrm{~K}$ to $1.9 \mathrm{~K}$ as compared to the binary of $3 \mathrm{~T}$. This also represents a $50 \%$ improvement over earlier production results. but was $30 \%$ lower than the similar binary at $5 \mathrm{~T}$. $4.2 \mathrm{~K}$ and slightly better at $10.0 \mathrm{~T}, 2.0 \mathrm{~K}$ than the best binary produced up to that time.

There were a series of short 'Tevatron' collared dipoles (minus the warm iron yoke) assembled and additionally clamped with large aluminum rings that were constructed during that time period ${ }^{11}$. The intent of this series of dipoles was to vary only one design parameter and fully characterize the magne.1 and it's subsequent performance. One of these dipoles was constructed using the ternary and several with binary conductor having slightly smaller or larger filaments which had similar critical currents at $4.2 \mathrm{~K}$. The binary dipole had a predicted ultimate $4.2 \mathrm{~K}$ performance of 6200 Amps and attained a repeatable current of 6150 Amps (5.10T) at $4.25 \mathrm{~K}$. The ternary dipole had a predicted performance of 6300 Amps and attained a repeatable current of 6070 Amps $(5.04 \mathrm{~T})$ at $4.25 \mathrm{~K}$. Subsequently, these dipoles were placed in a one atmosphere superfluid helium fixture and repeatedly quenched until a plateau current was determined. The binary dipole achieved the level predicted by the cable measurement with a plateatu value of $7150 \pm 20 \mathrm{Amps}(5.93 \mathrm{~T})$ at $1.9 \mathrm{~K}$. The ternary dipole slightly surpassed the cable current value with a plateau value of $7560 \pm 40$ Amps $(6.18 \mathrm{~T})$ at $1.9 \mathrm{~K}$. Therefore, the dipole's limit was slightly higher than the anticipated current due to increased $\mathrm{Hc}_{2}$ alone.

There were several changes made for the second "HiHo" (high gradient quad) production billet, both in alloy and assembly. These were in part dictated by the increased knowledge of the binary obtained in the UW metallurgical characterization and fabrication studies $10,12,13$ done in collaboration with the U.S. manufacturers for "SSC" Superconducting Super Collider cables. These changes were as follows: A) The percentage of $\mathrm{Ti}$ was increased by $3 \mathrm{w} / \mathrm{o}(44.4 \mathrm{w} / 0)$ to increase a rather sluggish optimization response of the previous alloy. This, in light of the subsequent data obtained for this alloy proved to be an error. The correct modification of the alloy would have been to increase the Ta content 2 to $5 \mathrm{w} / \mathrm{o}$ and leave the $\mathrm{Ti}$ content alone. The subsequent $\mathrm{Tc}(\mathrm{H})$ measurements indicated that we reduced the critical temperature "Tc" by about $200 \mathrm{mK}$ and therefore had offset most of the increased $\mathrm{Hc}_{2}$. B) The alloy was more homogenized ( $<2$ w/o global and local variations). This was one of the reasons the former alloy had not optimized as well as thought possible. C) The material had a diffusion barrier ( $\mathrm{Nb}$ ) added so that more aggressive heat treatments could be attempted without forming $\mathrm{Ti}-\mathrm{Cu}$ intermetallics which distort the fine filament arrays during area reduction. D) The interfilament distance was decreased to minimize the geometry distortion of the filament array. E) The interfilament copper was extruded on 
the $\mathrm{Nb}$ wrapped NbTiTa alloy. This step simplifies the fabrication process. F) A larger $30 \mathrm{~cm}$ diameter composite extrusion billet was used. It was loaded with the composite rods in a cold worked state. This provided larger strain space in which to heat treat and optimize the final strand. There were ten binary billets processed so far with the same geometry and similar histories. All these have been fabricated for the high gradient lens system therefore providing an excellent basis for comparison to the ternary. The ternary billet prototype samples achieved $\mathrm{Jc}(5 \mathrm{~T}, 4.2 \mathrm{~K})=$ $3100 \mathrm{~A} / \mathrm{mm}^{2}$ and $\mathrm{Jc}(8 \mathrm{~T}, 4.2 \mathrm{~K})=1050 \mathrm{~A} / \mathrm{mm}^{2}$ as compared to the binary $\mathrm{Jc}(5 \mathrm{~T}, 4.2 \mathrm{~K})=3150$. $3300 \mathrm{~A} / \mathrm{mm}^{2}$ (See Figure 1) and $\mathrm{Jc}(8 \mathrm{~T}, 4.2 \mathrm{~K})=$ $1380 \mathrm{~A} / \mathrm{mm}^{2}$ (See Figure 2). The low temperature shift of the ternary "Jc" was not $4 \mathrm{~T}$ as had been the previous $25 \mathrm{~cm}$ billet experience; i.e., Jc (XT, $4.2 \mathrm{~K}$ ) Jc $((X+4) T, 2.0 K)$. The present alloy results indicate that the corresponding increase is only $\sim 3.4-3.2 \mathrm{~T}$. The Jc $(10 \mathrm{~T}, 1.9 \mathrm{~K})$ of the best "HiHo" sample (See Figure 3) measured to date is $2075 \mathrm{~A} / \mathrm{mm}^{2}$. The bulk of the $30 \mathrm{~cm}$ billet ternary conductor remains to be fabricated and measured. The cause of the lower $\mathrm{Hc}_{2}$ for the "HiHo" alloy as compared to the earlier one appears to be the additional "Ti".

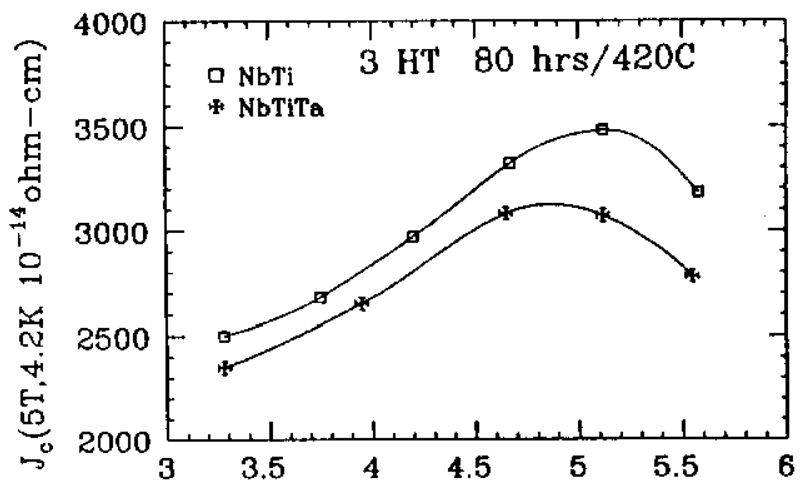

True strain after last heat treatment

FIGURE 1 - THIS REPRESENTS THE OPTIMUM ' $J C$ ' ACHIEVED TO DATE.

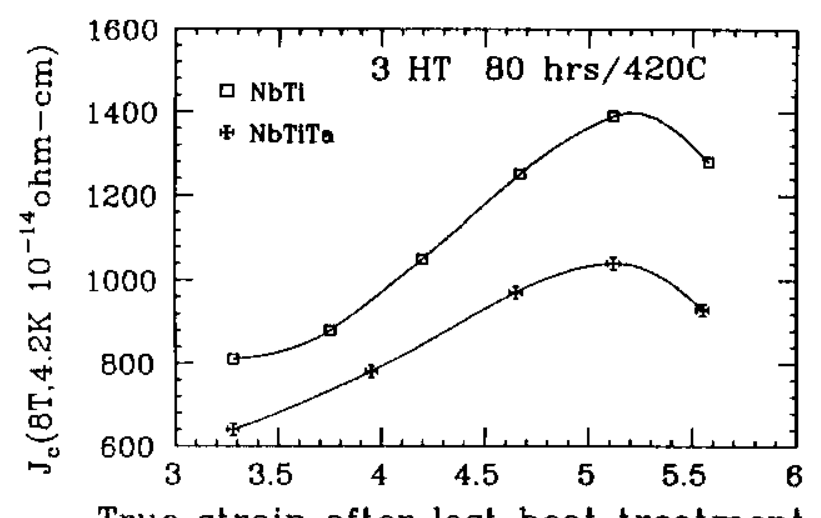

True strain after last heat treatment

FIgURE 2 - THESE ARE THE CURVES CORRESPONDING TO DATA IN FIG, 1 AT 8T.

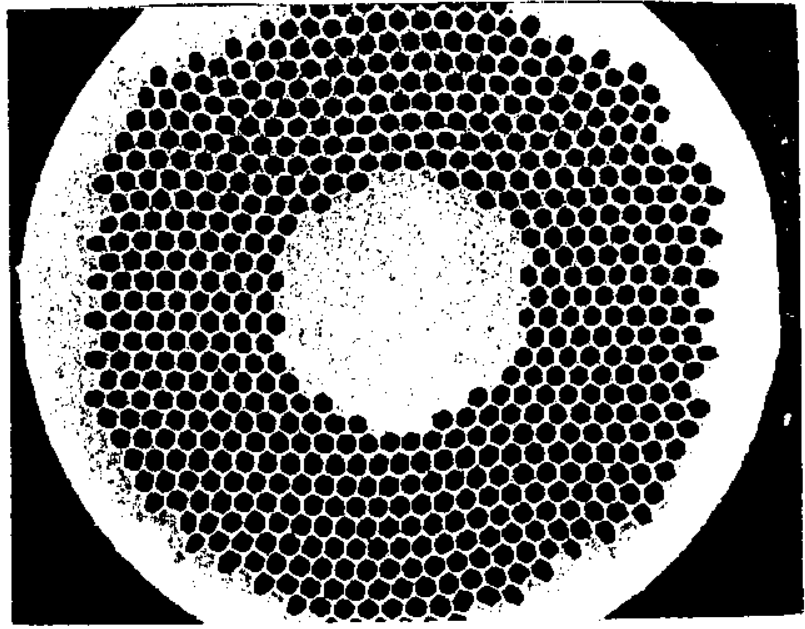

Figure 3 - PHOTOMICROgRAPH OF HIHO TERNARY BILLET CROSS SECTION.

\section{REFERENCES}

[1] A.D. McInturff, "High Field Magnet Proposal", FNAL TM1425, 1985.

[2] Dø Low Beta Quadrupole Requirements and Specifications \#2, Nov., 1986. TS Division, FNAL, "The Pink Book".

[3] M. Suenaga, R.M. Ralls, I. Appl. Phys., 40:4457 (1969).

[4] H.R. Segal, T.A. deWinter, ZJ.J. Stekly, and K. Hemachalam, IEEE TRANS. Magn., Vol. MAG-17, p.53, 1981.

[5] D.G. Hawksworth, D.C. Larbalestier, IEEE TRANS. Mag 17, 49 (1981).

[6] D.G. Hawksworth, Ph.D. Thesis, University of Wisconsin-Madison, 1981.

[7] K. Watanabe, K. Noto, Y. Moto, Y. Kamisada, E. Suzuki, Prac. of Int. Symp. on Flux Pinning and Electromagnetic Properties In Superconductors; Ed. T. Matsushita, K. Yamafuji, F. Ine, Matsokama Press, Japan, p. 220, (1986).

[8] H. Wada, K. Tachikawa, T. Kato, IEEE TRANS Mag. 17, 1, (1981).

[9] M. Wake, T. Shintomi, M. Kobayashi, K.. Tsuchiya, H. Hirabayashi, H. Wada, K. Inoue, K. Itoh, K. Tachikawa, K. Ishibashi, and A.D. McInturff, IEEE TRANS. Mag. 19, 3 (1983), pp. 552-555.

[10] D.C. Larbalestier, A.W. West, W.S. Starch, W. Warnes, P. Lee, W.K. McDonald, P.M. O'Larey, K. Hemachalam, B. Zeitlein, R. Scanlan, C. Taylor, IEEE TRANS. Mag. 21, p. 269 (1985)

[11] A.D. McInturff, J. Carson, N. Engler, H. Fisk, R. Hanft, R. Lundy, P. Mantsch, T. Nicol, R. Niemann, E. Schmidt, and A. Szymulanski, IEEE TRANS Mag. 21. No. 2, (1985), pp. 478-481.

[12] D. Larbalestier, A.W. West, Action Met, University of Wisconsin Group, Summary Talk for the Workshops, 32, p. 1871, (1984).

[13] P.J. Lee, D. Larbalestier, University of Wisconsin Group, Summary Talk for the Workshops, Multigraphical, Action Met, 35, p. 2523, (1987). 